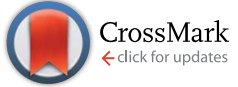

Cite this: RSC Adv., 2017, 7, 1833

Received 5th October 2016

Accepted 10th December 2016

DOI: $10.1039 / c 6 r a 24769 e$

www.rsc.org/advances

\section{Amphipathic monolith-supported palladium catalysts for chemoselective hydrogenation and cross-coupling reactions $\uparrow$}

\author{
Yasunari Monguchi, ${ }^{* a}$ Fumika Wakayama, ${ }^{a}$ Shun Ueda, ${ }^{a}$ Ryo Ito, ${ }^{a}$ Hitoshi Takada, \\ Hiroshi Inoue, ${ }^{\mathrm{b}}$ Akira Nakamura, ${ }^{\mathrm{b}}$ Yoshinari Sawama ${ }^{\mathrm{a}}$ and Hironao Sajiki ${ }^{\star a}$
}

A palladium catalyst immobilized on an amphipathic and monolithic polystyrene-divinylbenzene polymer bearing strongly acidic cation exchange functions (sulfonic acid moieties) (Pd/CM) was developed. It was used as a catalyst for hydrogenation and ligand-free cross-coupling reactions, such as the SuzukiMiyaura, Mizoroki-Heck, and copper- and amine-free Sonogashira-type reactions, together with a palladium catalyst supported on monolithic polymer (Pd/AM) bearing basic anion exchange functions (ammonium salt moieties), which has been in practical use for the decomposition of hydrogen peroxide produced as a byproduct during the manufacture of ultrapure water. While the $\mathrm{Pd} / \mathrm{CM}$ was highly active as a catalyst for the hydrogenation and a variety of reducible functional groups could be reduced, the use of $\mathrm{Pd} / \mathrm{AM}$ led to a unique chemoselective hydrogenation. Aromatic carbonyl groups were tolerant under the $\mathrm{Pd} / \mathrm{AM}$-catalyzed hydrogenation conditions, although benzyl esters, benzyl ethers, and $\mathrm{N}$ - $\mathrm{Cbz}$ groups could be smoothly hydrocracked. The cross-coupling reactions readily proceeded using either catalyst. The palladium leaching from the Pd/CM into the reaction media was never observed during the Sonogashira-type reaction, which was hardly achieved by other palladium-supported heterogeneous catalysts due to the good affinity of the palladium species with alkynes.

\section{Introduction}

The development of heterogeneous palladium catalysts is an important subject in organic chemistry from environmental and economical viewpoints based on their recovery, reuse, and non-metal residual property. ${ }^{1} \mathrm{~A}$ wide variety of organic polymers possessing some functional groups within the molecule, which could act as ligands toward palladium species, has been used as supports for the heterogeneous palladium catalysts, especially for cross-coupling reactions. ${ }^{2,3}$ The variation in the supports of palladium catalysts is also known to affect the catalyst activity for hydrogenation, ${ }^{4}$ and we have developed a variety of heterogeneous palladium catalysts for chemoselective hydrogenation, such as palladium fibroin $(\mathrm{Pd} / \mathrm{Fib}),{ }^{5}$ palladium on synthetic adsorbent (Pd/HP20), ${ }^{2 b, c}$ palladium on molecular sieves $(\mathrm{Pd} /$ $\mathrm{MS}){ }^{6}$ palladium on boron nitride $(\mathrm{Pd} / \mathrm{BN}),{ }^{7}$ palladium on chelate resin $(\mathrm{Pd} / \mathrm{CR} 11$ and $\mathrm{Pd} / \mathrm{CR} 20),{ }^{8}$ and palladium on ceramic $\left(\mathrm{Pd} /\right.$ ceramic). ${ }^{9}$

\footnotetext{
${ }^{a}$ Laboratory of Organic Chemistry, Gifu Pharmaceutical University, 1-25-4 Daigaku-nishi, Gifu 501-1196, Japan. E-mail: monguchi@gifu-pu.ac.jp; sajiki@ gifu-pu.ac.jp; Fax: +8158230 8109; Tel: +81 582308109

${ }^{b} R \& D$ Center, Organo Corporation, 4-4-1 Nishionuma, Minami-Ku, Sagamihara 2520332, Japan

$\dagger$ Electronic supplementary information (ESI) available: Experimental details, spectral data and NMR spectra of products. See DOI: 10.1039/c6ra24769e
}

Monolithic polymers are supposed to be good supports for the palladium catalysts based on the effective incorporation of substrates into the porous supports, and such catalysts are expected to be used for flow reactions due to the excellent permeability of the reaction solution without resistance to the fluid flow. Palladium catalysts immobilized on polystyrenebased monolithic polymers bearing quaternary ammonium salts as the anion exchange functions have been used under flow conditions for the cross-coupling reactions, such as the Suzuki-Miyaura, Mizoroki-Heck, and Sonogashira-type reactions, and transfer hydrogenation in the absence of hydrogen gas. ${ }^{10}$ Other types of palladium catalysts supported on monolithic polymers derived from ferritin bionanoparticles, ${ }^{11}$ $N$-aminoethylamidine-bound polyacrylonitrile, ${ }^{12}$ and Shiff basebound acrylate ${ }^{13}$ were also reported as effective catalysts for the Suzuki-Miyaura reaction ${ }^{11-13}$ under batch conditions and flow hydrogenation. ${ }^{11}$

A polystyrene-based monolithic polymer bearing quaternary ammonium moieties (AM) has been in practical use as a support for the palladium catalyst (Pd/AM), which decomposes hydrogen peroxide produced as a byproduct during the UV irradiation process to degrade contaminated trace organic substances for manufacturing ultrapure water. $^{14}$ The polystyrene-based monolithic polymer bearing sulfonic acid moieties as cationic exchange functions (CM) are also manufactured.$^{15}$ We anticipated that the hydrophilic sulfonic acid 
moieties would facilitate the incorporation of palladium species on/in the porous monolithic polymer in analogy with Pd/AM. Such ammonium and sulfonic acid moieties were expected to function as ligands for cross-coupling reactions and also as catalyst poisons for chemoselective hydrogenation based on the appropriate coordination to palladium metals. ${ }^{4 a}$ Furthermore, the amphipathic and porous nature of the supports would provide a broad substrate scope due to an easy access of both hydrophobic and hydrophilic substrates to the catalyst metals. $^{3 e, 16}$ In this paper, we demonstrate the development of a novel palladium catalyst supported on $\mathrm{CM}(\mathrm{Pd} / \mathrm{CM})$ as well as the application of both $\mathrm{Pd} / \mathrm{AM}$ and $\mathrm{Pd} / \mathrm{CM}$ to several organic reactions; i.e., hydrogenation and cross-coupling reactions under batch conditions.

\section{Results and discussion}

\section{Preparation of palladium on monolith- $\mathrm{SO}_{3} \mathrm{H}(\mathrm{Pd} / \mathrm{CM})$}

The unfunctionalized monolithic polymer was first prepared through the two successive polymerization processes from styrene and divinylbenzene using sorbitan fatty acid ester as an emulsifier, radical initiators, such as 2,2'-azobis(isobutyronitrile), and water according to a previously reported method (Fig. 1). ${ }^{14}$ Subsequently, the sulfonic acid function was introduced to the resulting plain monolithic polymer by the general method for the preparation of a strongly acidic cation exchange resin using chlorosulfuric acid. ${ }^{15}$ The colorless monolith- $\mathrm{SO}_{3} \mathrm{H}$ polymer (CM) was cut into $1 \mathrm{~mm}$ cubes using a ceramic knife, then immersed in a reddish $\mathrm{Pd}(\mathrm{OAc})_{2}$ solution of $\mathrm{MeOH}$. After the mixture was stirred at room temperature under an $\mathrm{Ar}$ atmosphere for $24 \mathrm{~h}$, the solution became colorless, and the colorless CM was time-dependently changed to brown by the absorption of divalent palladium species. The brown CM was treated with hydrazine hydrate in water to give the zero valent palladium-supported black CM, which was collected on filter paper, washed with $\mathrm{MeOH}$ and water, and dried in vacuo to give

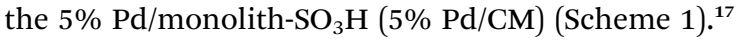

A transmission electron microscope (TEM) image of the $5 \%$ $\mathrm{Pd} / \mathrm{CM}$ shows that the palladium nanoparticles (approximately 5-10 nm) aggregate to form 5-30 nm size clusters (Fig. 2), which

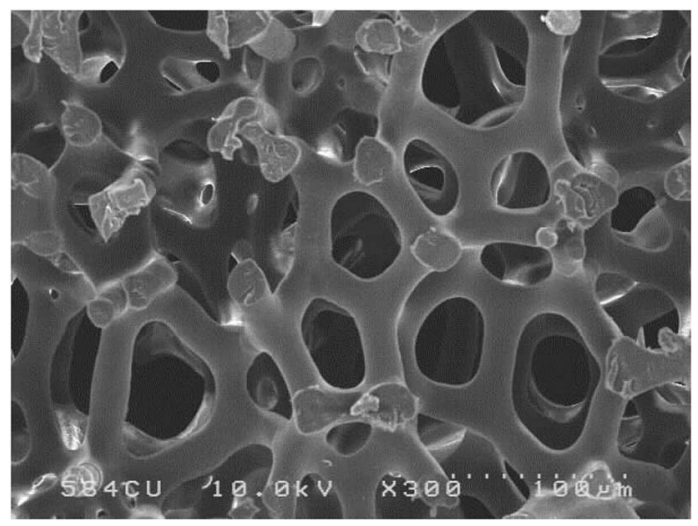

Fig. 1 SEM image of unfunctionlized monolithic polymer.

\begin{tabular}{|c|c|c|c|}
\hline & 1) $\mathrm{Pd}(\mathrm{OAc})_{2}$ & 1) $\mathrm{NH}_{2} \mathrm{NH}_{2} \cdot \mathrm{H}_{2} \mathrm{O}$ & \\
\hline Monolith- $\mathrm{SO}_{3} \mathrm{H}$ & $\mathrm{MeOH}, \mathrm{rt}, 24 \mathrm{~h}$ & $\mathrm{rt}, 24 \mathrm{~h}$ & $5 \% \mathrm{Pd} /$ monolith $-\mathrm{SO}_{3} \mathrm{H}$ \\
\hline (CM) & $\begin{array}{l}\text { 2) filtration/wash } \\
\text { 3) drying }\end{array}$ & $\begin{array}{l}\text { 2) filtration/wash } \\
\text { 3) drying }\end{array}$ & (5\% Pd/CM) \\
\hline
\end{tabular}

Scheme 1 Preparation of $5 \% \mathrm{Pd} /$ monolith- $\mathrm{SO}_{3} \mathrm{H}(\mathrm{Pd} / \mathrm{CM})$.

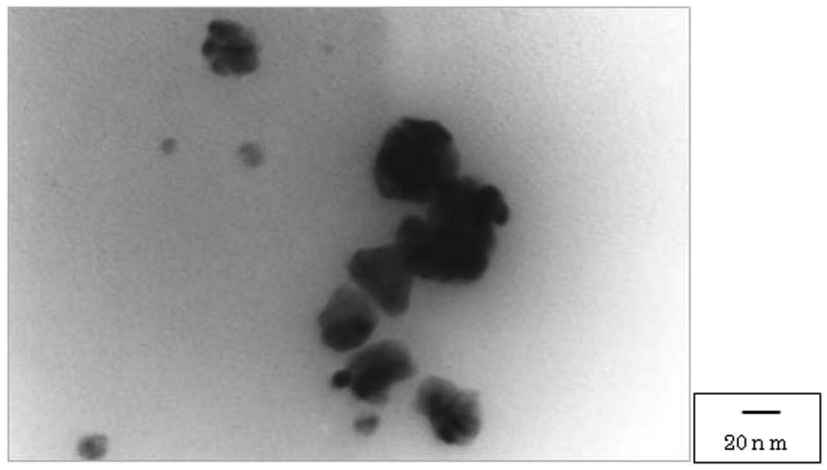

Fig. 2 TEM image of 5\% Pd/CM.

were revealed to be evenly distributed from the surface of the $5 \% \mathrm{Pd} / \mathrm{CM}$ to the inside by an electron probe microanalysis (EPMA) (Fig. 3). The aggregation pattern of palladium species as well as the palladium lording on $5 \% \mathrm{Pd} / \mathrm{CM}$ was quite similar to the case of $3.9 \% \mathrm{Pd} / \mathrm{AM}^{18}$

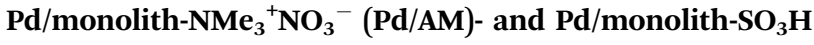 (Pd/CM)-catalyzed hydrogenation}

The catalytic activity of the $3.9 \% \mathrm{Pd} /$ monolith- $\mathrm{NMe}_{3}{ }^{+} \mathrm{NO}_{3}{ }^{-}(\mathrm{Pd} /$ $\mathrm{AM})^{19}$ and 5\% Pd/CM for the hydrogenation of various reducible functionalities was first evaluated (Table 1). Alkyne (entries 1, 2, 29, and 30), alkene (entries 3, 4, 13-20, 25, and 26), azido (entries 5 and 6), and nitro (entries 7 and 8) functionalities were readily reduced to the corresponding products in good yields by either catalyst. These catalysts can also be used for the deprotection of aromatic (entries 9 and 10) and aliphatic $\mathrm{N}-\mathrm{Cbz}$ groups (entries 11-16), benzyl esters (entries 17, 18, 21, and 22),

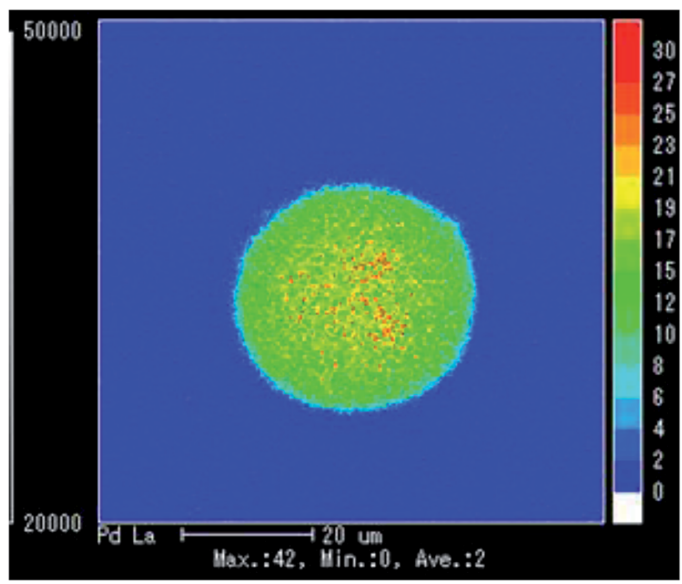

Fig. 3 EPMA of $5 \% \mathrm{Pd} / \mathrm{CM}$. 
Table $13.9 \% \mathrm{Pd} / \mathrm{AM}$ - and 5\% Pd/CM-catalyzed hydrogenations

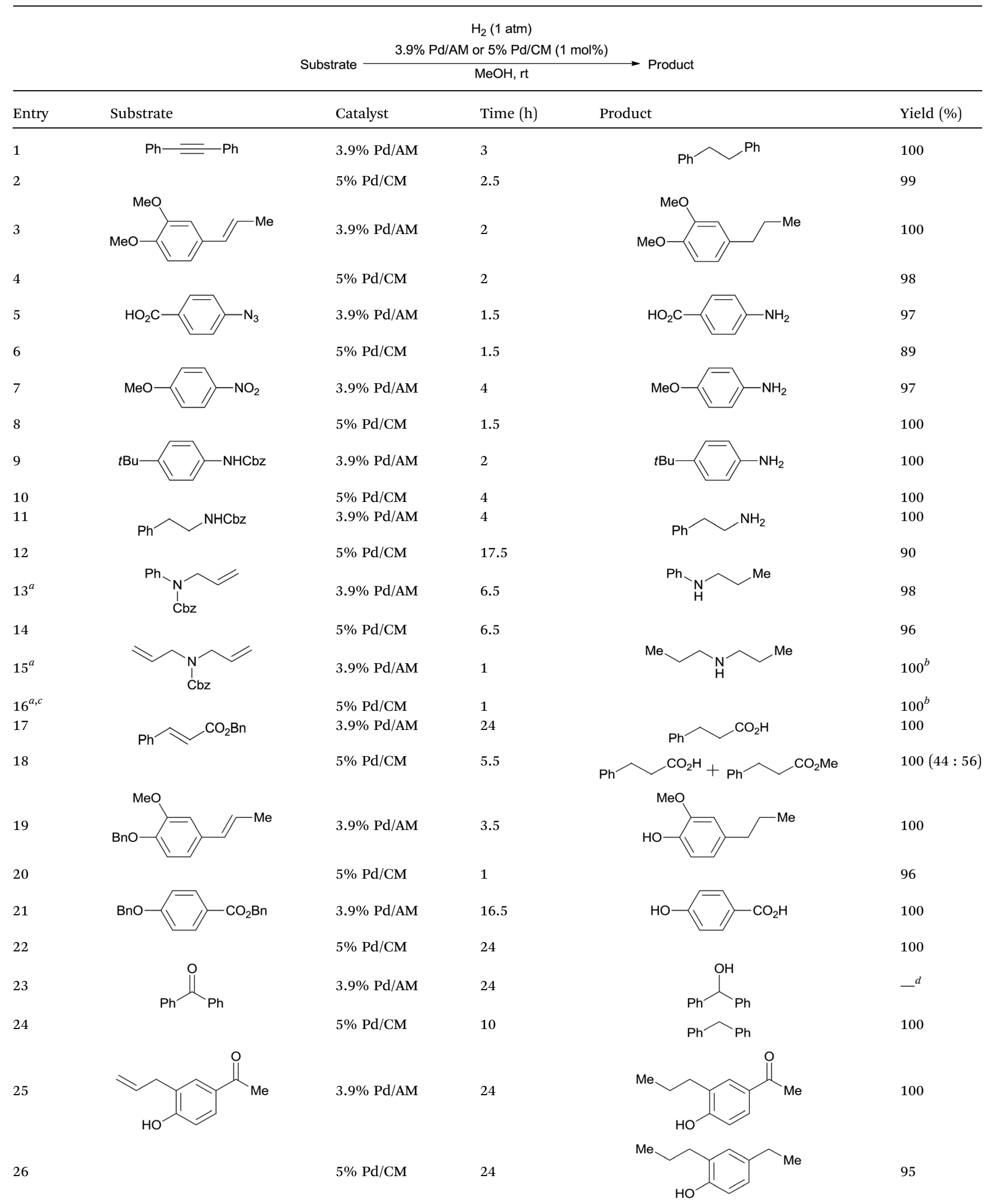




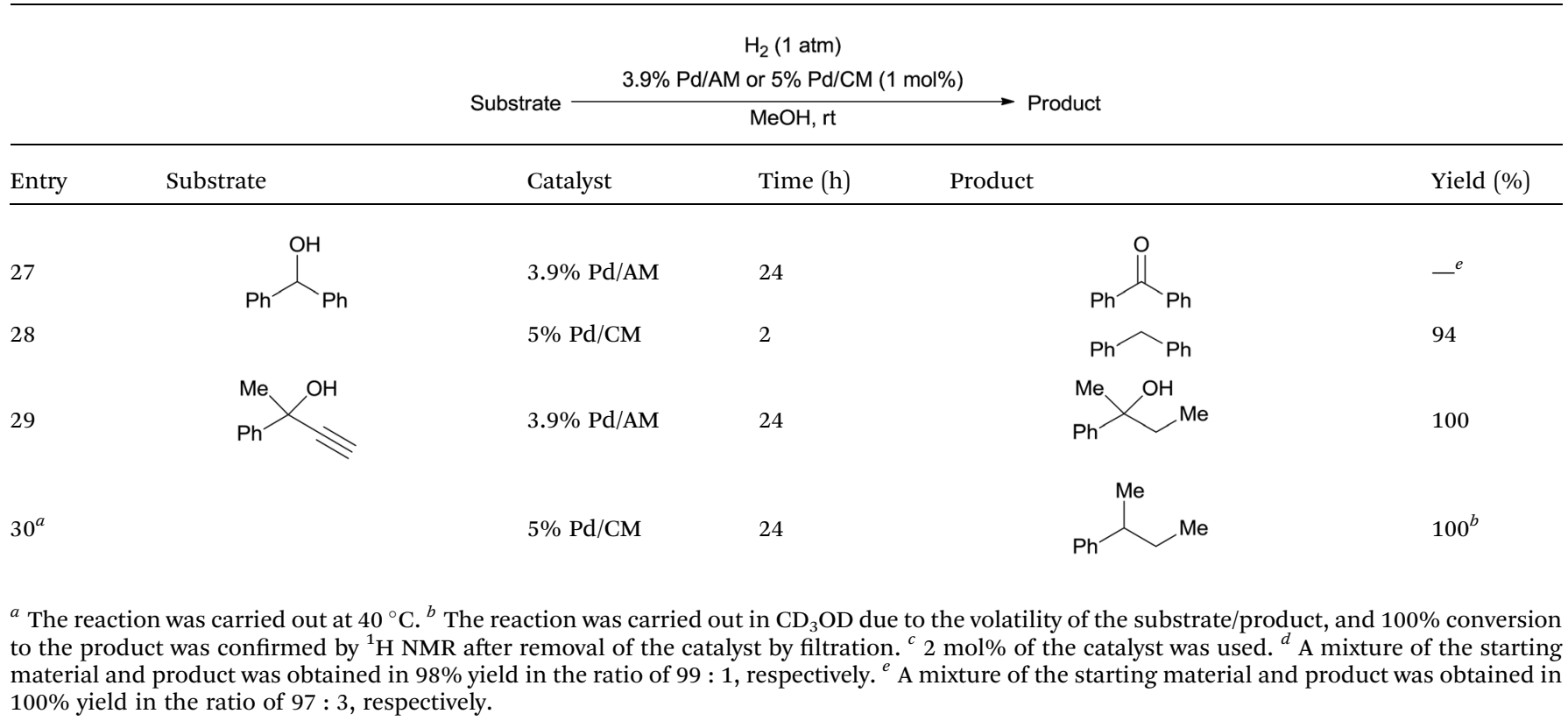

and aryl benzyl ethers (entries 19-22), although the benzyl ester underwent partial transesterification with $\mathrm{MeOH}$ to afford the methyl ester due to the strong acidity of the support (CM) of $\mathrm{Pd}$ / CM (entry 18). While the Pd/CM effectively catalyzed the hydrogenolysis of aromatic ketones (entries 24 and 26) and benzyl alcohols (entries 24, 26, 28, and 30) to give the corresponding deoxygenated products, these reducible functionalities were virtually untouched under the Pd/AM-catalyzed conditions (entries 23, 25, 27, and 29). An exposition of benzhydrol under the Pd/AM-catalyzed hydrogenation conditions afforded a very small amount of the dehydrogenated product, benzophenone (entry 27). The different chemoselectivity toward the hydrogenolysis of aromatic carbonyls and benzyl alcohols, i.e., higher activity of $5 \% \mathrm{Pd} / \mathrm{CM}$ compared with $3.9 \% \mathrm{Pd} / \mathrm{AM}$, would be attributed to the strong Brønsted acidity of CM; thus, the activation of carbonyl groups and benzyl alcohols by the protonation would promote the reactions.

The catalyst activities of the $3.9 \% \mathrm{Pd} / \mathrm{AM}$ and $5 \% \mathrm{Pd} / \mathrm{CM}$ together with catalysts previously developed by us are summarized in Fig. 4. The reducible functional groups in the specific frameworks could be reduced using the corresponding catalysts. While $5 \% \mathrm{Pd} / \mathrm{CM}$ can catalyze the hydrogenation of a wide range of reducible functionalities as with $\mathrm{Pd} / \mathrm{C}$ and $\mathrm{Pd} / \mathrm{HP} 20,{ }^{2 b}$ the use of $3.9 \% \mathrm{Pd} / \mathrm{AM}$ makes it possible to undergo a novel hydrogenation, i.e., aromatic carbonyl groups are tolerant, while $N$-Cbz, benzyl ester, and aryl benzyl ether can be hydrocracked.

\section{Pd/AM- and Pd/CM-catalyzed cross-coupling reactions}

The Suzuki-Miyaura coupling reaction between aryl bromides and arylboronic acids (1.5 equiv.) were carried out using 0.5 $\mathrm{mol} \% \mathrm{Pd} / \mathrm{AM}$ or $\mathrm{Pd} / \mathrm{CM}$ and $\mathrm{Na}_{3} \mathrm{PO}_{4} \cdot 12 \mathrm{H}_{2} \mathrm{O}$ (3.5 equiv.) in $50 \%$ aqueous $i \mathrm{PrOH}$ (Table 2). Although the reaction time was dependent on the kind of aryl bromides, the desired biaryls

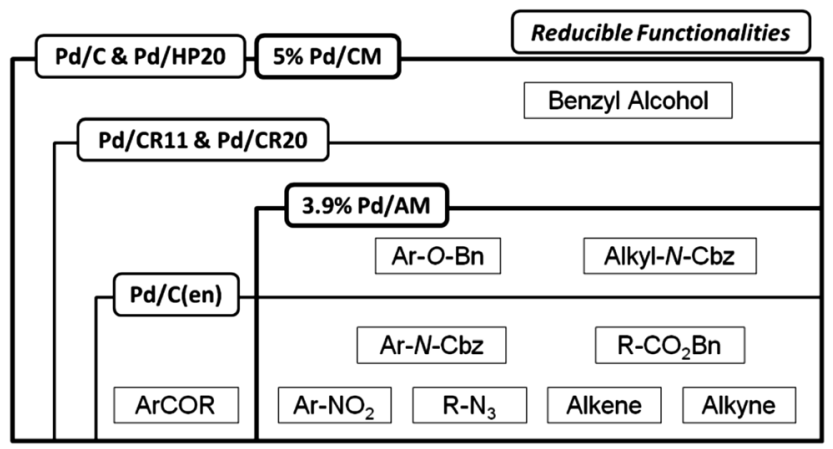

Fig. 4 Chemoselectivity of 3.9\% Pd/AM- and 5\% Pd/CM-catalyzed hydrogenation.

could be smoothly obtained using either $3.9 \% \mathrm{Pd} / \mathrm{AM}$ or $5 \% \mathrm{Pd} /$ $\mathrm{CM}$ at room temperature as is the case in $10 \% \mathrm{Pd} / \mathrm{C}$ that we have previously reported. ${ }^{20}$ The phenylation of the non-protected free bromoaniline was completed within only $1.5 \mathrm{~h}$ (entries 10 and 11), while $24 \mathrm{~h}$ was not long enough for the reaction completion by $10 \% \mathrm{Pd} / \mathrm{C}$ (entry 12 ). These results were probably caused by the hydrophilicity of the amino group, and the bromoaniline could be more effectively absorbed into the amphipathic monolith.

The 0.2 mol\% of $3.9 \%$ Pd/AM- or $5 \%$ Pd/CM-catalyzed Mizoroki-Heck reaction of aryl iodides with benzyl acrylate (1.2 equiv.) in the presence of $\mathrm{Bu}_{3} \mathrm{~N}$ (1.1 equiv.) in $N, N$-dimethylacetamide (DMA) at $100{ }^{\circ} \mathrm{C}$ efficiently proceeded regardless of the electronic property of the substituent on the benzene ring of the aryl iodides to give the corresponding butyl cinnamate derivatives in excellent yields (Table 3, entries 1, 2, 4, 5, 7, 8, 10, and 11). The $3.9 \% \mathrm{Pd} / \mathrm{AM}$ or $5 \% \mathrm{Pd} / \mathrm{CM}$ catalyzed the cross-coupling between iodobenzene and styrene in a manner similar to $10 \%$ Pd/HP20 (entries 13-15). ${ }^{2 c}$ It is notable that both catalysts 
Table 2 3.9\% Pd/AM- and 5\% Pd/CM-catalyzed Suzuki-Miyaura reactions<smiles>[R]c1ccc(Br)cc1</smiles>

1.1 equiv

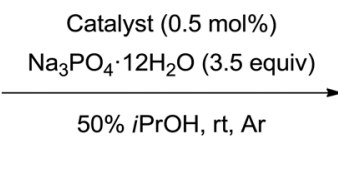

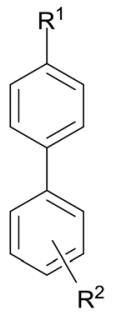

$\mathrm{R}^{2}$

\begin{tabular}{|c|c|c|c|c|c|}
\hline Entry & $\mathrm{R}^{1}$ & $\mathrm{R}^{2}$ & Catalyst & Time (h) & Yield (\%) \\
\hline 1 & \multirow[t]{3}{*}{$\mathrm{NO}_{2}$} & \multirow[t]{3}{*}{$\mathrm{H}$} & $3.9 \% \mathrm{Pd} / \mathrm{AM}$ & 24 & 93 \\
\hline 2 & & & $5 \% \mathrm{Pd} / \mathrm{CM}$ & 6 & 92 \\
\hline $3^{a}$ & & & $10 \% \mathrm{Pd} / \mathrm{C}$ & 3.5 & 93 \\
\hline 4 & \multirow[t]{3}{*}{$\mathrm{CO}_{2} \mathrm{Et}$} & \multirow[t]{3}{*}{$\mathrm{H}$} & $3.9 \% \mathrm{Pd} / \mathrm{AM}$ & 24 & 99 \\
\hline 5 & & & 5\% Pd/CM & 2 & 96 \\
\hline $6^{a}$ & & & $10 \% \mathrm{Pd} / \mathrm{C}$ & 6 & 99 \\
\hline 7 & \multirow[t]{3}{*}{$\mathrm{CO}_{2} \mathrm{H}$} & \multirow[t]{3}{*}{$\mathrm{H}$} & $3.9 \% \mathrm{Pd} / \mathrm{AM}$ & 7 & 96 \\
\hline 8 & & & $5 \% \mathrm{Pd} / \mathrm{CM}$ & 7 & 100 \\
\hline $9^{a}$ & & & $10 \% \mathrm{Pd} / \mathrm{C}$ & 3.5 & 100 \\
\hline $10^{b}$ & \multirow[t]{3}{*}{$\mathrm{NH}_{2}$} & \multirow[t]{3}{*}{$\mathrm{H}$} & $3.9 \% \mathrm{Pd} / \mathrm{AM}$ & 0.5 & 95 \\
\hline $11^{b}$ & & & 5\% Pd/CM & 1.5 & 84 \\
\hline $12^{b, c}$ & & & $10 \% \mathrm{Pd} / \mathrm{C}$ & 24 & 65 \\
\hline 13 & \multirow[t]{3}{*}{$\mathrm{OMe}$} & \multirow[t]{3}{*}{$\mathrm{H}$} & $3.9 \% \mathrm{Pd} / \mathrm{AM}$ & 24 & 94 \\
\hline 14 & & & 5\% Pd/CM & 19 & 97 \\
\hline $15^{a}$ & & & $10 \% \mathrm{Pd} / \mathrm{C}$ & 24 & 93 \\
\hline 16 & \multirow[t]{3}{*}{$\mathrm{OH}$} & \multirow[t]{3}{*}{$\mathrm{H}$} & $3.9 \% \mathrm{Pd} / \mathrm{AM}$ & 24 & 94 \\
\hline 17 & & & 5\% Pd/CM & 24 & 96 \\
\hline $18^{a}$ & & & $10 \% \mathrm{Pd} / \mathrm{C}$ & 3.5 & 91 \\
\hline $19^{d}$ & \multirow[t]{3}{*}{$\mathrm{OMe}$} & \multirow[t]{3}{*}{ 2-OMe } & $3.9 \% \mathrm{Pd} / \mathrm{AM}$ & 12 & 86 \\
\hline $20^{d}$ & & & 5\% Pd/CM & 4 & 94 \\
\hline $21^{a}$ & & & $10 \% \mathrm{Pd} / \mathrm{C}$ & 6 & 90 \\
\hline 22 & \multirow[t]{3}{*}{$\mathrm{NO}_{2}$} & \multirow[t]{3}{*}{ 4-Ac } & $3.9 \% \mathrm{Pd} / \mathrm{AM}$ & 23 & 98 \\
\hline 23 & & & 5\% Pd/CM & 2 & 88 \\
\hline $24^{c}$ & & & $10 \% \mathrm{Pd} / \mathrm{C}$ & 12 & 91 \\
\hline
\end{tabular}

${ }^{a}$ Results from ref. $20{ }^{b} 80{ }^{\circ} \mathrm{C} .{ }^{c}$ Results from ref. $2 c .{ }^{d}$ The reaction was carried out in $\mathrm{H}_{2} \mathrm{O}$.

effectively worked for the $\beta$-phenylation of the acryl amide and acrylonitrile (entries 16,17,19, and 20), the catalyst efficiency of which was quite low under the Pd/HP20-catalyzed conditions (entries 18 and 21). The polarity of the functional groups (trimethylammonium and sulfonic acid) on the monolith resin would increase the affinity for polar substrates in comparison to the simple polystyrene-divinyl benzene-based polymer of HP20 thus leading to the enhanced reaction efficiency.

The $3.9 \% \mathrm{Pd} / \mathrm{AM}$ and $5 \% \mathrm{Pd} / \mathrm{CM}$ could be used for the copperand amine-free Sonogashira-type reaction in the absence of ligands (Table 4). A wide variety of aryl iodides coupled with aromatic or aliphatic alkynes (1.2 equiv.) in the presence of 0.4 $\mathrm{mol} \%$ of $3.9 \% \mathrm{Pd} / \mathrm{AM}$ or $5 \% \mathrm{Pd} / \mathrm{CM}$ in $50 \%$ aqueous $i \mathrm{PrOH}$ at $80{ }^{\circ} \mathrm{C}$ afforded the corresponding disubstituted alkynes.

\section{Reuse test of Pd/AM and Pd/CM for hydrogenation and Sonogashira-type reaction}

After the Pd/AM- and Pd/CM-catalyzed hydrogenations of 1,2dimethoxy-4-(1-propenyl)benzene in $\mathrm{MeOH}$ at room

Table 3 3.9\% Pd/AM- and 5\% Pd/CM-catalyzed Mizoroki-Heck reactions

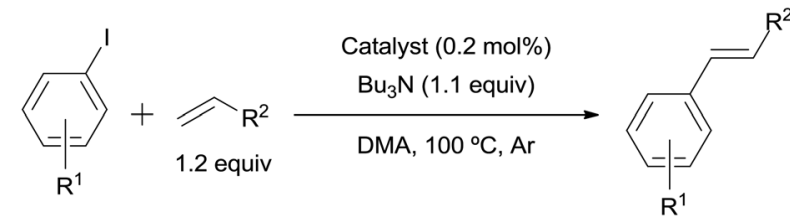

\begin{tabular}{|c|c|c|c|c|c|}
\hline Entry & $\mathrm{R}^{1}$ & $\mathrm{R}^{2}$ & Catalyst & Time (h) & Yield (\%) \\
\hline 1 & \multirow[t]{3}{*}{$4-\mathrm{NO}_{2}$} & \multirow[t]{3}{*}{$\mathrm{CO}_{2} \mathrm{Bu}$} & $3.9 \% \mathrm{Pd} / \mathrm{AM}$ & 5.5 & 80 \\
\hline $2^{a}$ & & & 5\% Pd/CM & 24 & 88 \\
\hline $3^{b}$ & & & $10 \% \mathrm{Pd} / \mathrm{HP} 20$ & 4 & 81 \\
\hline 4 & \multirow[t]{3}{*}{$3-\mathrm{NO}_{2}$} & \multirow[t]{3}{*}{$\mathrm{CO}_{2} \mathrm{Bu}$} & 3.9\% Pd/AM & 5 & 84 \\
\hline 5 & & & $5 \% \mathrm{Pd} / \mathrm{CM}$ & 6 & 75 \\
\hline $6^{b}$ & & & $10 \% \mathrm{Pd} / \mathrm{HP} 20$ & 24 & 98 \\
\hline 7 & \multirow[t]{3}{*}{ 4-Me } & \multirow[t]{3}{*}{$\mathrm{CO}_{2} \mathrm{Bu}$} & $3.9 \% \mathrm{Pd} / \mathrm{AM}$ & 7 & 92 \\
\hline 8 & & & $5 \% \mathrm{Pd} / \mathrm{CM}$ & 4 & 99 \\
\hline $9^{b}$ & & & $10 \% \mathrm{Pd} / \mathrm{HP} 20$ & 24 & 93 \\
\hline 10 & \multirow[t]{3}{*}{$\mathrm{H}$} & \multirow[t]{3}{*}{$\mathrm{CO}_{2} \mathrm{Bu}$} & 3.9\% Pd/AM & 4 & 100 \\
\hline 11 & & & $5 \% \mathrm{Pd} / \mathrm{CM}$ & 3 & 91 \\
\hline $12^{b}$ & & & $10 \% \mathrm{Pd} / \mathrm{HP} 20$ & 4 & 95 \\
\hline $13^{a}$ & \multirow[t]{3}{*}{$\mathrm{H}$} & \multirow[t]{3}{*}{$\mathrm{Ph}$} & $3.9 \% \mathrm{Pd} / \mathrm{AM}$ & 24 & 52 \\
\hline $14^{a}$ & & & $5 \% \mathrm{Pd} / \mathrm{CM}$ & 24 & 61 \\
\hline $15^{b}$ & & & $10 \% \mathrm{Pd} / \mathrm{HP} 20$ & 24 & 64 \\
\hline $16^{a}$ & \multirow[t]{3}{*}{$\mathrm{H}$} & \multirow[t]{3}{*}{$\mathrm{CONH}_{2}$} & $3.9 \% \mathrm{Pd} / \mathrm{AM}$ & 17.5 & 93 \\
\hline $17^{a}$ & & & $5 \% \mathrm{Pd} / \mathrm{CM}$ & 9 & 88 \\
\hline $18^{b}$ & & & $10 \% \mathrm{Pd} / \mathrm{HP} 20$ & 24 & 65 \\
\hline $19^{c}$ & \multirow[t]{3}{*}{$\mathrm{H}$} & \multirow[t]{3}{*}{$\mathrm{CN}$} & $3.9 \% \mathrm{Pd} / \mathrm{AM}$ & 24 & $94(E / Z=85: 15)$ \\
\hline $20^{c}$ & & & $5 \% \mathrm{Pd} / \mathrm{CM}$ & 6.5 & $88(E / Z=86: 14)$ \\
\hline $21^{b, c}$ & & & $10 \% \mathrm{Pd} / \mathrm{HP} 20$ & 12 & $73(E / Z=86: 14)$ \\
\hline
\end{tabular}

${ }^{a} 80{ }^{\circ}$ C. ${ }^{b}$ Results from ref. $2 c .{ }^{c} 2$ mol\% of catalyst was used.

temperature, the palladium species leached into the filtrate were measured by atomic absorption spectrometry. In each case, no palladium species were observed in the filtrate within the detectable limits $(<1 \mathrm{ppm})$. Therefore, the hydrogenation would be expected to cause no or little degradation to the Pd/AM and $\mathrm{Pd} / \mathrm{CM}$, and they could be reused until at least the $5^{\text {th }}$ run without any loss of catalyst activities (Table 5).

We have previously reported that approximately $25 \%$ of the palladium metal was leached from $10 \% \mathrm{Pd} / \mathrm{C}$ during the copperand amine-free $\mathrm{Pd} / \mathrm{C}$-catalyzed Sonogashira-type reaction between 4 -iodoacetophenone and 3-butyn-1-ol [inductively coupled plasma-atomic emission spectrometry (ICP-AES)], ${ }^{21}$ and the catalyst could be reused only once. The use of simple polystyrene-divinylbenzene copolymer-supported $10 \% \mathrm{Pd} / \mathrm{HP} 20$ for the reaction of $4^{\prime}$-iodoacetophenone with ethynylbenzene led to a reduction in the palladium leaching ratio to $2.4 \%$ probably due to the relatively strong interaction between the palladium species and aromatic rings of HP20. ${ }^{2 c}$ Since no detectable palladium leaching from $\mathrm{Pd} / \mathrm{C}$ and $\mathrm{Pd} / \mathrm{HP} 20$ has been observed in the cases of other cross-coupling reactions, such as the Suzuki-Miyaura ${ }^{2 c, 20}$ and Mizoroki-Heck ${ }^{2 c}$ reactions, the significant palladium leaching during the copper-free, heterogeneous Sonogashira-type reaction is an important issue that needs to be addressed. While a very small amount of palladium leaching $(1.9 \%)$ was observed when $3.9 \% \mathrm{Pd} / \mathrm{AM}$ was used for the cross- 
Table 4 3.9\% Pd/AM- and 5\% Pd/CM-catalyzed Sonogashira-type reactions

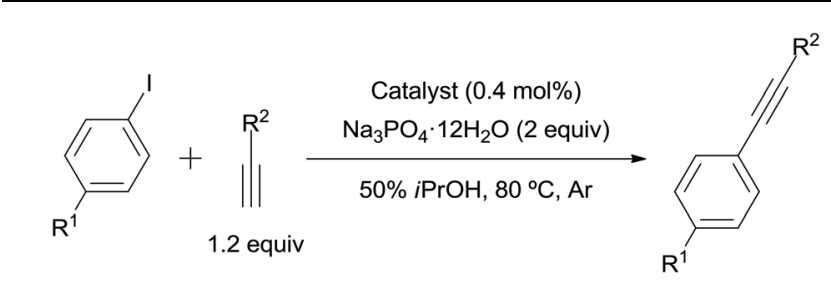

\begin{tabular}{llllll}
\hline Entry & $\mathrm{R}^{1}$ & $\mathrm{R}^{2}$ & Catalyst & Time (h) & Yield (\%) \\
\hline 1 & \multirow{2}{*}{$\mathrm{Ac}$} & $\mathrm{Ph}$ & $3.9 \% \mathrm{Pd} / \mathrm{AM}$ & 1 & 99 \\
2 & & & $5 \% \mathrm{Pd} / \mathrm{CM}$ & 1 & 100 \\
$3^{a}$ & & & $10 \% \mathrm{Pd} / \mathrm{C}$ & 0.5 & 95 \\
4 & $\mathrm{OMe}$ & $\mathrm{Ph}$ & $3.9 \% \mathrm{Pd} / \mathrm{AM}$ & 17.5 & 61 \\
$5^{b}$ & & & $5 \% \mathrm{Pd} / \mathrm{CM}$ & 24 & 61 \\
$6^{a}$ & & & $10 \% \mathrm{Pd} / \mathrm{C}$ & 0.5 & 51 \\
7 & $\mathrm{H}$ & $\mathrm{Ph}$ & $3.9 \% \mathrm{Pd} / \mathrm{AM}$ & 1 & 56 \\
8 & & & $5 \% \mathrm{Pd} / \mathrm{CM}$ & 1 & 64 \\
$9^{a}$ & & & $10 \% \mathrm{Pd} / \mathrm{C}$ & 0.5 & 66 \\
10 & $\mathrm{Ac}$ & $2-\mathrm{CF}_{3} \mathrm{C}_{6} \mathrm{H}_{4}$ & $3.9 \% \mathrm{Pd} / \mathrm{AM}$ & 1 & 87 \\
11 & & & $5 \% \mathrm{Pd} / \mathrm{CM}$ & 1 & 84 \\
$12^{a}$ & & & $10 \% \mathrm{Pd} / \mathrm{C}$ & 1 & 90 \\
13 & $\mathrm{Ac}$ & $\left(\mathrm{CH}_{2}\right)_{2} \mathrm{OH}$ & $3.9 \% \mathrm{Pd} / \mathrm{AM}$ & 7 & 79 \\
14 & & & $5 \% \mathrm{Pd} / \mathrm{CM}$ & 1 & 76 \\
$15^{a}$ & & & $10 \% \mathrm{Pd} / \mathrm{C}$ & 1 & 85 \\
16 & Ac & $4-\mathrm{MeC}_{6} \mathrm{H}_{4}$ & $3.9 \% \mathrm{Pd} / \mathrm{AM}$ & 4 & 94 \\
17 & & & $5 \% \mathrm{Pd} / \mathrm{CM}$ & 4 & 80
\end{tabular}

${ }^{a}$ Results from ref. $21 .{ }^{b} 2$ equiv. of ethynylbenzene were used.

coupling reaction between $4^{\prime}$-iodoacetophenone and ethynylbenzene, palladium species were never detected by ICP-AES in the case of the $5 \% \mathrm{Pd} / \mathrm{CM}$. The less palladium leaching would be arisen from the good interaction of palladium metals with functional groups on the highly porous monolithic polymer. Hence, the reuse test of the $5 \% \mathrm{Pd} / \mathrm{CM}$ was investigated (Table 6). The weight of the recovered Pd/CM after the first run increased compared to the initial use probably because of the partial or full exchange of protons of the monolith- $\mathrm{SO}_{3} \mathrm{H}$ to the sodium cations of $\mathrm{Na}_{3} \mathrm{PO}_{4} \cdot 12 \mathrm{H}_{2} \mathrm{O}$. The recovered catalyst was

Table 5 Reuse test of Pd/AM and Pd/CM for hydrogenation

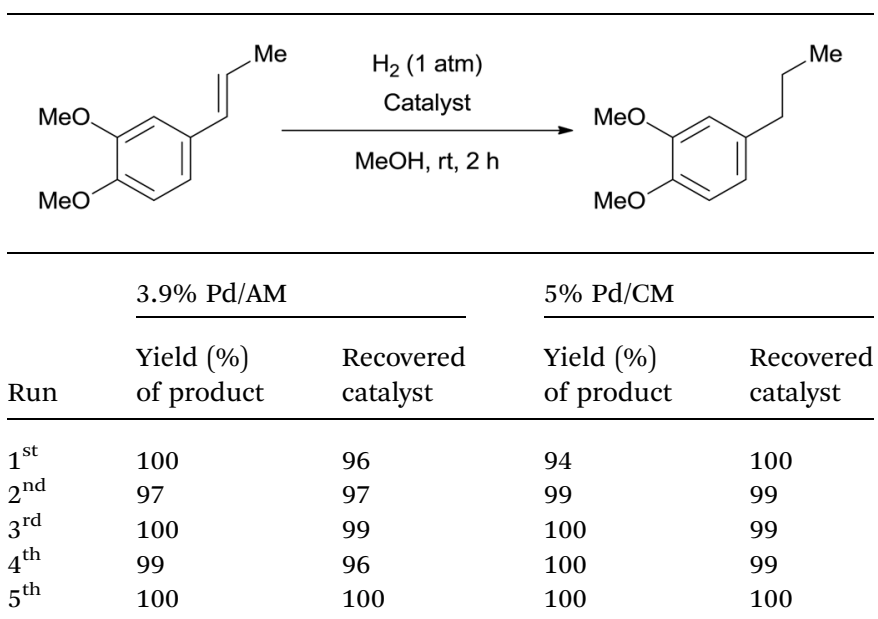

Table 6 Reuse test of 5\% Pd/CM for Sonogashira-type reaction

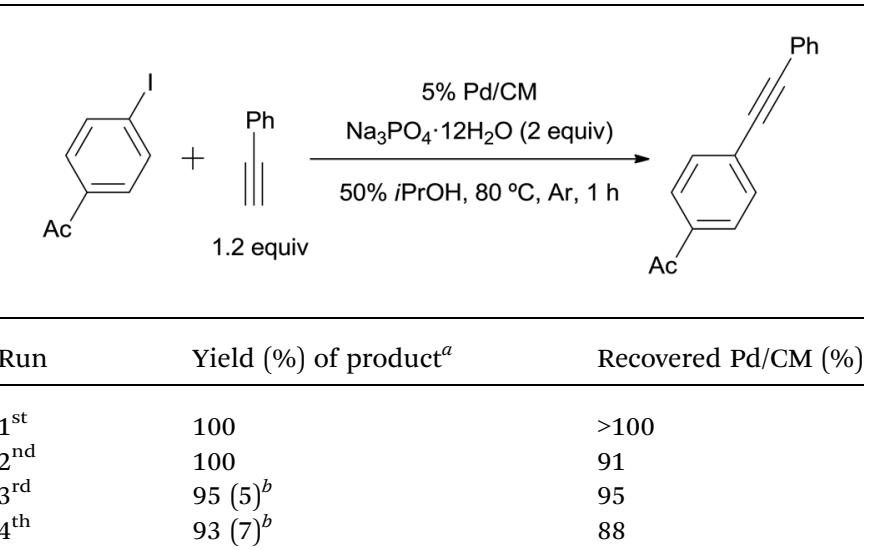

${ }^{a}$ Determined by ${ }^{1} \mathrm{H}$ NMR using 1,4-dioxane as the internal standard.

${ }^{b}$ Yield of recovered $4^{\prime}$-iodoacetophenone.

used for the second run without any further acid treatment, and no increase in the weight of the recovered catalyst was observed after the second run. Although the catalyst activity only slightly decreased after the fourth run, the catalyst could be reused without any significant decrease in the catalyst activity. The palladium leaching-free and reusable properties of the copperand amine-free Sonogashira-type reaction are remarkable advantages of the $5 \% \mathrm{Pd} /$ monolith- $\mathrm{SO}_{3} \mathrm{H}$.

\section{Conclusions}

A palladium catalyst supported on the amphipathic, monolithic polystyrene-divinylbenzene polymer bearing ammonium functions (Pd/AM) as well as a newly-developed sulfonic acid-bound monolithic polymer-supported palladium ( $\mathrm{Pd} / \mathrm{CM}$ ) could be used for hydrogenation reactions. It is noteworthy that a novel chemoselective hydrogenation was successively achieved under the Pd/AM-catalyzed conditions; aromatic ketones could not be reduced to the corresponding benzyl alcohols, and benzyl alcohols were also intact, while Pd/CM catalyzed the hydrogenation of various reducible functionalities. Both catalysts were applicable for the ligand-free cross-coupling reactions, SuzukiMiyaura, Mizoroki-Heck, and copper- and amine-free Sonogashira-type reactions. When $\mathrm{Pd} / \mathrm{CM}$ was used for the Sonogashira-type reaction, no palladium leaching into the reaction media was observed despite the use of an alkyne as a substrate. Furthermore, $\mathrm{Pd} / \mathrm{CM}$ could be recovered and reused for the Sonogashira-type reactions for at least four runs. The application of these catalysts for the flow reactions is now ongoing in our laboratory.

\section{Experimental}

\section{Preparation of 5\% Pd/CM (Scheme 1)}

The monolith- $\mathrm{SO}_{3} \mathrm{H}$ polymer (CM) was cut into $1 \mathrm{~mm}$ cubes using a ceramic knife, washed with $\mathrm{H}_{2} \mathrm{O}$ and $\mathrm{MeOH}$, and dried overnight under reduced pressure. The dried CM (1.00 g) was immersed in a solution of $\mathrm{Pd}(\mathrm{OAc})_{2}[111 \mathrm{mg}, 495 \mu \mathrm{mol}$ 
(52.6779 $\mathrm{mg}$ for $\mathrm{Pd})]$ in $\mathrm{MeOH}(30 \mathrm{~mL})$, and stirred at room temperature under an Ar atmosphere for $24 \mathrm{~h}$. The resulting brown polymer was collected on a Kiriyama funnel $(1 \mu \mathrm{m})$, washed with $\mathrm{MeOH}(5 \times 20 \mathrm{~mL})$ and $\mathrm{H}_{2} \mathrm{O}(5 \times 20 \mathrm{~mL})$, then $\mathrm{MeOH}(5 \times 20 \mathrm{~mL})$, and dried under vacuum for $12 \mathrm{~h}$. The filtrate was concentrated in vacuo, then transferred to a $100 \mathrm{~mL}$ volumetric flask with $\mathrm{H}_{2} \mathrm{O}$. Its atomic absorption analysis indicated that $0.32224 \mathrm{mg} \mathrm{L}^{-1}(32.224 \mu \mathrm{g})$ of palladium species was present. To a suspension of the collected solid in $\mathrm{H}_{2} \mathrm{O}(20 \mathrm{~mL})$ was added $\mathrm{NH}_{2} \mathrm{NH}_{2} \cdot \mathrm{H}_{2} \mathrm{O}(74.3 \mathrm{mg}, 1.47 \mathrm{mmol})$, and the mixture was stirred at room temperature under an $\mathrm{Ar}$ atmosphere for $24 \mathrm{~h}$. The black solid was collected on a Kiriyama funnel $(1 \mu \mathrm{m})$, washed with $\mathrm{H}_{2} \mathrm{O}(5 \times 20 \mathrm{~mL})$ and $\mathrm{MeOH}(5 \times 20 \mathrm{~mL})$, then dried under vacuum for $24 \mathrm{~h}$ to produce the $\mathrm{Pd} / \mathrm{CM}(1.05 \mathrm{~g})$. The filtrate was concentrated in vacuo, then transferred to a $100 \mathrm{~mL}$ volumetric flask with $\mathrm{H}_{2} \mathrm{O}$. Its atomic absorption analysis indicated that $0.82912 \mathrm{mg} \mathrm{L}^{-1}(82.912 \mu \mathrm{g})$ of the palladium species was present. The palladium amount, which was not captured on the CM, was found to be $115.136 \mu \mathrm{g}(32.224+82.912 \mu \mathrm{g})$, which means that the palladium ratio of $\mathrm{Pd} / \mathrm{CM}$ was $5.0 \%$ $[(52.6779-0.115136) / 1050 \times 100]$.

\section{Typical procedure for the 3.9\% Pd/AM- and 5\% Pd/CM- catalyzed hydrogenation (Table 1 )}

A mixture of the substrate $(200 \mu \mathrm{mol})$ and $3.9 \% \mathrm{Pd} / \mathrm{AM}(5.5 \mathrm{mg}$, $2.00 \mu \mathrm{mol})$ or $5 \% \mathrm{Pd} / \mathrm{CM}(4.3 \mathrm{mg}, 2.00 \mu \mathrm{mol})$ in $\mathrm{MeOH}(1 \mathrm{~mL})$ was stirred under an $\mathrm{H}_{2}$ atmosphere (balloon) at room temperature for a specific time, then passed through a cotton filter to remove the catalyst. The filtrate was concentrated in vacuo to give the analytically pure product. The spectral data of the product were identical to those in the literature.

\section{Typical procedure for the 3.9\% Pd/AM- and 5\% Pd/CM-} catalyzed Suzuki-Miyaura reactions (Table 2)

A mixture of the aryl halide $(500 \mu \mathrm{mol})$, arylboronic acid (550 $\mu \mathrm{mol}), \mathrm{Na}_{3} \mathrm{PO}_{4} \cdot 12 \mathrm{H}_{2} \mathrm{O}(665 \mathrm{mg}, 1.75 \mathrm{mmol})$ and $\mathrm{Pd} / \mathrm{AM}(6.8 \mathrm{mg}$, $2.50 \mu \mathrm{mol})$ or $\mathrm{Pd} / \mathrm{CM}(5.3 \mathrm{mg}, 2.50 \mu \mathrm{mol})$ in $\mathrm{H}_{2} \mathrm{O}(1 \mathrm{~mL})-i$ PrOH $(1 \mathrm{~mL})$ or in $\mathrm{H}_{2} \mathrm{O}(2 \mathrm{~mL})$ in a test tube under an Ar atmosphere was stirred at room temperature or $80{ }^{\circ} \mathrm{C}$. After complete consumption of the aryl halide was confirmed by TLC analyses or after $24 \mathrm{~h}$ (if the reaction was incomplete), the mixture was passed through a cotton filter to remove the catalyst. To the filtrate were added EtOAc $(20 \mathrm{~mL})$ and saturated aqueous $\mathrm{NH}_{4} \mathrm{Cl}$ $(20 \mathrm{~mL})$, then the layers were separated. The organic layer was washed with saturated aqueous $\mathrm{NH}_{4} \mathrm{Cl}(2 \times 20 \mathrm{~mL})$ and brine $(20 \mathrm{~mL})$, dried over $\mathrm{MgSO}_{4}$, filtered, and concentrated in vacuo. The residue was purified by flash silica gel column chromatography ( $n$-hexane/EtOAc or $\mathrm{CH}_{2} \mathrm{Cl}_{2} / \mathrm{MeOH} / \mathrm{AcOH}$ ) to give the corresponding biaryl. The spectral data of the product were identical to those in the literature.

Typical procedure for the 3.9\% Pd/AM- and 5\% Pd/CMcatalyzed Mizoroki-Heck reactions (Table 3)

A mixture of the aryl iodide $(500 \mu \mathrm{mol})$, mono-substituted alkene $(600 \mu \mathrm{mol}), \mathrm{Bu}_{3} \mathrm{~N}(102 \mathrm{mg}, 550 \mu \mathrm{mol})$, and $\mathrm{Pd} / \mathrm{AM}$ $(2.7 \mathrm{mg}, 1.00 \mu \mathrm{mol})$ or $\mathrm{Pd} / \mathrm{CM}(2.1 \mathrm{mg}, 1.00 \mu \mathrm{mol})$ in DMA
$(2 \mathrm{~mL})$ in a test tube under an Ar atmosphere was stirred at $100{ }^{\circ} \mathrm{C}$ or $80^{\circ} \mathrm{C}$. After complete consumption of the aryl iodide was confirmed by TLC analyses or after $24 \mathrm{~h}$ (if the reaction was incomplete), the mixture was passed through a cotton filter to remove the catalyst. To the filtrate were added EtOAc $(20 \mathrm{~mL})$ and saturated aqueous $\mathrm{NH}_{4} \mathrm{Cl}(20 \mathrm{~mL})$, then the layers were separated. The organic layer was washed with saturated aq. $\mathrm{NH}_{4} \mathrm{Cl}(2 \times 20 \mathrm{~mL})$ and brine $(20 \mathrm{~mL})$, dried over $\mathrm{MgSO}_{4}$, and concentrated in vacuo. The residue was purified by silica gel flash column chromatography ( $n$-hexane/EtOAc) to give the corresponding disubstituted alkene derivative. The spectral data of the product were identical to those in the literature. For entries 19 and 20, the reactions were performed using $2 \mathrm{~mol} \%$ of Pd/AM $(27.3 \mathrm{mg}, 10.0 \mu \mathrm{mol})$ or Pd/CM $(21.3 \mathrm{mg}, 10.0 \mu \mathrm{mol})$.

\section{Typical procedure for the 3.9\% Pd/AM- and 5\% Pd/CM- catalyzed Sonogashira-type reactions (Table 4)}

A mixture of the aryl iodide $(500 \mu \mathrm{mol})$, the mono-substituted alkyne $(600 \mu \mathrm{mol}), \mathrm{Na}_{3} \mathrm{PO}_{4} \cdot 12 \mathrm{H}_{2} \mathrm{O}(380 \mathrm{mg}, 1.00 \mathrm{mmol})$ and $\mathrm{Pd} / \mathrm{AM}(5.5 \mathrm{mg}, 2.00 \mu \mathrm{mol})$ or $\mathrm{Pd} / \mathrm{CM}(4.3 \mathrm{mg}, 2.00 \mu \mathrm{mol})$ in $\mathrm{H}_{2} \mathrm{O}$ $(1 \mathrm{~mL})-i \operatorname{PrOH}(1 \mathrm{~mL})$ in a test tube under an $\mathrm{Ar}$ atmosphere was stirred at $80^{\circ} \mathrm{C}$. After complete consumption of the aryl iodide was confirmed by TLC analyses, the mixture was passed through a cotton filter to remove the catalyst. To the filtrate were added EtOAc $(20 \mathrm{~mL})$ and saturated aqueous $\mathrm{NH}_{4} \mathrm{Cl}(20 \mathrm{~mL})$, then the layers were separated. The organic layer was washed with saturated aqueous $\mathrm{NH}_{4} \mathrm{Cl}(2 \times 20 \mathrm{~mL})$ and brine $(20 \mathrm{~mL})$, dried over $\mathrm{MgSO}_{4}$, filtered, and concentrated in vacuo. The residue was purified by flash silica gel column chromatography (n-hexane/EtOAc) to give the corresponding disubstituted alkyne. The spectral data of the product were identical to those in the literature. For entry 5 , the reaction was performed using 2 equiv. of ethynylbenzene $(102 \mathrm{mg}, 1.00 \mathrm{mmol})$.

\section{Notes and references}

1 (a) L. Yin and J. Liebscher, Chem. Rev., 2007, 107, 133; (b) M. J. Climent, A. Corma and S. Iborra, Chem. Rev., 2011, 111, 1072.

2 For unfunctionalized polymer as the support: (a) R. Akiyama and S. Kobayashi, Angew. Chem., Int. Ed., 2001, 40, 3469; Angew. Chem., 2001, 113, 3577; (b) Y. Monguchi, Y. Fujita, K. Endo, S. Takao, M. Yoshimura, Y. Takagi, T. Maegawa and H. Sajiki, Chem.-Eur. J., 2009, 15, 834; (c) Y. Monguchi, K. Sakai, K. Endo, Y. Fujita, M. Niimura, M. Yoshimura, T. Mizusaki, Y. Sawama and H. Sajiki, ChemCatChem, 2012, 4, 546.

3 (a) D. Sengupta, J. Saha, G. De and B. Basu, J. Mater. Chem. A, 2014, 2, 3986; (b) V. Pandarus, D. Desplantier-Giscard, G. Gingras, F. Béland, R. Ciriminna and M. Pagliaro, Org. Process Res. Dev., 2013, 17, 1492; (c) B. Tamami, M. M. Nezhad, S. Ghasemi and F. Farjadian, J. Organomet. Chem., 2013, 743, 10; (d) M. Bakherad, A. Keivanloo and S. Samangooei, Tetrahedron Lett., 2012, 53, 5773; (e) Y. M. A. Yamada, S. M. Sarkar and Y. Uozumi, J. Am. Chem. Soc., 2012, 134, 3190; (f) G. Li, H. Yang, W. Li and 
G. Zhang, Green Chem., 2011, 13, 2939; $(g)$ B. Karimi and P. F. Akhavan, Inorg. Chem., 2011, 50, 6063; $(h)$ P. Das, D. Sharma, A. K. Shil and A. Kumari, Tetrahedron Lett., 2011, 52, 1176; ( $i$ ) M.-J. Jin and D.-H. Lee, Angew. Chem., Int. Ed., 2010, 49, 1119; Angew. Chem., 2010, 122, 1137; (j) D.-H. Lee, M. Choi, B.-W. Yu, R. Ryoo, A. Taher, S. Hossain and M.-J. Jin, Adv. Synth. Catal., 2009, 351, 2912; (k) B. Basu, S. Das, P. Das, B. Mandal, D. Banerjee and F. Almqvist, Synthesis, 2009, 7, 1137; (l) S. Schweizer, J.-M. Becht and C. L. Drian, Org. Lett., 2007, 9, 3777; (m) R. Sayah, K. Glegola, E. Framery and V. Dufaud, Adv. Synth. Catal., 2007, 349, 373; (n) L. Wu, B.-O. Li, Y.-Y. Huang, H.-F. Zhou, Y.-M. He and Q.-H. Fan, Org. Lett., 2006, 8, 3605; (o) K. Okamoto, R. Akiyama, H. Yoshida, T. Yoshida and S. Kobayashi, J. Am. Chem. Soc., 2005, 127, 2125; (p) A. N. Cammidge, N. J. Baines and R. K. Bellingham, Chem. Commun., 2001, 2588.

4 (a) Y. Yabe, Y. Sawama, Y. Monguchi and H. Sajiki, Catal. Sci. Technol., 2014, 4, 260; (b) H.-Y. Lee, S. Ryu, H. Kang, Y.-w. Jun and J. Cheon, Chem. Commun., 2006, 1325; (c) H. Hagiwara, T. Nakamura, T. Hoshi and T. Suzuki, Green Chem., 2011, 13, 1131; (d) M. Armbrüster, M. Behrens, F. Cinquini, K. Föttinger, Y. Grin, A. Haghofer, B. Klötzer, A. KnopGericke, H. Lorenz, A. Ota, S. Penner, J. Prinz, C. Rameshan, Z. Révay, D. Rosenthal, G. Rupperchter, P. Sautet, R. Schlögl, L. Shao, L. Szentmiklósi, D. Teschner, D. Torres, R. Wagner, R. Widmer and G. Wowsnick, ChemCatChem, 2012, 4, 1048; (e) M. V. Vasylyev, G. Maayan, Y. Hovav, A. Haimov and R. Neumann, Org. Lett., 2006, 8, 5445; ( $f$ ) J. Le Bras, D. K. Mukherjee, S. González, M. Tristany, B. Ganchegui, M. Moreno-Maňas, R. Pleixats, F. Henin and J. Muzart, New J. Chem., 2004, 28, 1550; $(g)$ E. Thiery, J. Le Bras and J. Muzart, Green Chem., 2007, 9, 326; (h) N. M. Callis, E. Thiery, J. Le Bras and J. Muzart, Tetrahedron Lett., 2007, 48, 8128.

5 (a) H. Sajiki, T. Ikawa and K. Hirota, Tetrahedron Lett., 2003, 44, 171; (b) H. Sajiki, T. Ikawa and K. Hirota, Tetrahedron Lett., 2003, 44, 8437; (c) T. Ikawa, H. Sajiki and K. Hirota, Tetrahedron, 2005, 61, 2217; (d) Y. Kitamura, A. Tanaka, M. Sato, K. Oono, T. Ikawa, T. Maegawa, Y. Monguchi and H. Sajiki, Synth. Commun., 2007, 37, 4381; (e) T. Ikawa, H. Sajiki and K. Hirota, J. Synth. Org. Chem., Jpn., 2005, 63, 1218.

6 (a) T. Maegawa, T. Takahashi, M. Yoshimura, H. Suzuka, Y. Monguchi and H. Sajiki, Adv. Synth. Catal., 2009, 351, 2091; (b) T. Takahashi, M. Yoshimura, H. Suzuka, T. Maegawa, Y. Sawama, Y. Monguchi and H. Sajiki, Tetrahedron, 2012, 68, 8293.

7 (a) Y. Yabe, T. Yamada, S. Nagata, Y. Sawama, Y. Monguchi and H. Sajiki, Adv. Synth. Catal., 2012, 354, 1264; (b) Y. Yabe, Y. Sawama, Y. Monguchi and H. Sajiki, Chem.-Eur. J., 2013, 19, 484; (c) A. Kawanishi, C. Miyamoto, Y. Yabe, M. Inai, T. Asakawa, Y. Hamashima, H. Sajiki and T. Kan, Org. Lett., 2013, 15, 1306; (d) Y. Yabe, Y. Sawama,
T. Yamada, S. Nagata, Y. Monguchi and H. Sajiki, ChemCatChem, 2013, 5, 2360.

8 Y. Monguchi, T. Ichikawa, K. Nozaki, K. Kihara, Y. Yamada, Y. Miyake, Y. Sawama and H. Sajiki, Tetrahedron, 2015, 71, 6499.

9 Y. Monguchi, T. Marumoto, T. Ichikawa, Y. Miyake, Y. Nagae, M. Yoshida, Y. Oumi, Y. Sawama and H. Sajiki, ChemCatChem, 2015, 7, 2155.

10 (a) K. Mennecke and A. Kirschning, Beilstein J. Org. Chem., 2009, 5, 21; (b) W. Solodenko, H. Wen, S. Leue, F. Stuhlmann, G. Sourkouni-Argirusi, G. Jas, H. Schönfeld, U. Kunz and A. Kirschning, Eur. J. Org. Chem., 2004, 3601; (c) K. Mennecke, R. Cecilia, T. N. Glasnov, S. Gruhl, C. Vogt, A. Feldhoff, M. A. L. Vargas, C. O. Kappe, U. Kunz and A. Kirschning, Adv. Synth. Catal., 2008, 350, 717.

11 S. Kumari, A. Kulkarni, G. Kumarasawamy and S. S. Gupta, Chem. Mater., 2013, 25, 4813.

12 D. Kundu, A. K. Patra, J. Sakamoto and H. Uyama, React. Funct. Polym., 2014, 79, 8.

13 M. Nandi and H. Uyama, RSC Adv., 2014, 4, 20847.

$14 \mathrm{H}$. Inoue, H. Takada and M. Murayama, Kobunshi Ronbunshu, 2011, 68, 320. Pd/AM was industrially produced by Organo Corporation according to the procedure described in Note and reference; ${ }^{14}$ palladium species were immobilized on the ammoniumfunctionalized monolithic polymer (AM), and then reduced with $\mathrm{NH}_{2} \mathrm{NH}_{2}$. The palladium loading was determined to be 3.9 weight\% by the inductively coupled plasma-atomic emission spectrometry (ICP-AES) after the degradation of Pd/AM using a microwave heating.

15 H. Inoue, K. Yamanaka, A. Yoshida, T. Aoki, T. Kaneko and M. Teraguchi, Kobunshi Ronbunshu, 2004, 61, 301.

16 Reviews including transition metal catalysts immobilized on amphipathic supports: (a) Á. Molnár, Chem. Rev., 2011, 111, 2251; (b) J. Lu and P. H. Toy, Chem. Rev., 2009, 109, 815; (c) S. Ikegami and H. Hamamoto, Chem. Rev., 2009, 109, 583.

$174.6 \mathrm{mmol} \mathrm{g}^{-1}$ of sulfonic acid groups are distributed evenly on the polymer, see the ESI. $\dagger$ The molar ratio of sulfonic acids to palladium metals is 9.8 .

18 The TEM image of $3.9 \% \mathrm{Pd} / \mathrm{AM}$ indicates that $10-30 \mathrm{~nm}-\mathrm{Pd}$ clusters are formed by the aggregation of Pd nanoparticles (approximately $5 \mathrm{~nm}$ ). The palladium species were found to be dispersed into the whole monolithic polymer by EPMA, although a partial localization of the species inside the monolithic polymer was also observed, see the ESI. $\dagger$

$194.3 \mathrm{mmol} \mathrm{g}^{-1}$ of ammonium groups are distributed evenly on the polymer, see the ESI. $\dagger$ The molar ratio of ammonium functionalities to palladium metals is 10.5 .

20 T. Maegawa, Y. Kitamura, S. Sako, T. Udzu, A. Sakurai, A. Tanaka, Y. Kobayashi, K. Endo, U. Bora, T. Kurita, A. Kozaki, Y. Monguchi and H. Sajiki, Chem.-Eur. J., 2007, 13, 5937.

21 S. Mori, T. Yanase, S. Aoyagi, Y. Monguchi, T. Maegawa and H. Sajiki, Chem.-Eur. J., 2008, 14, 6994. 